\title{
Simulation of Multi-Stage Fine Machining Processes at the Example of Valve Guide and Valve Seat
}

\author{
Christian Boelling ${ }^{1, a}{ }^{*}$ and Eberhard Abele $e^{1, b}$ \\ ${ }^{1}$ Institute of Production Management, Technology and Machine Tools (PTW), Technische \\ Universität Darmstadt, Otto-Berndt-Str. 2, 64287 Darmstadt, Germany \\ aBoelling@ptw.tu-darmstadt.de, ${ }^{b}$ Abele@ptw.tu-darmstadt.de
}

Keywords: Fine machining, Simulation, Uncertainty

Abstract. Fine machining processes are of great importance in automotive series production, e.g. the machining of valve guide and seat in the cylinder head of a combustion engine. In industrial manufacturing processes, disturbances are inevitable and provide a measure of uncertainty in each production step. Increasingly, the influence of such uncertainties is being evaluated using simulation models. In this paper, a modeling approach for simulation of multi-stage fine machining processes with step tools is presented and investigations regarding influence of uncertainty caused by disturbances are performed.

\section{Introduction}

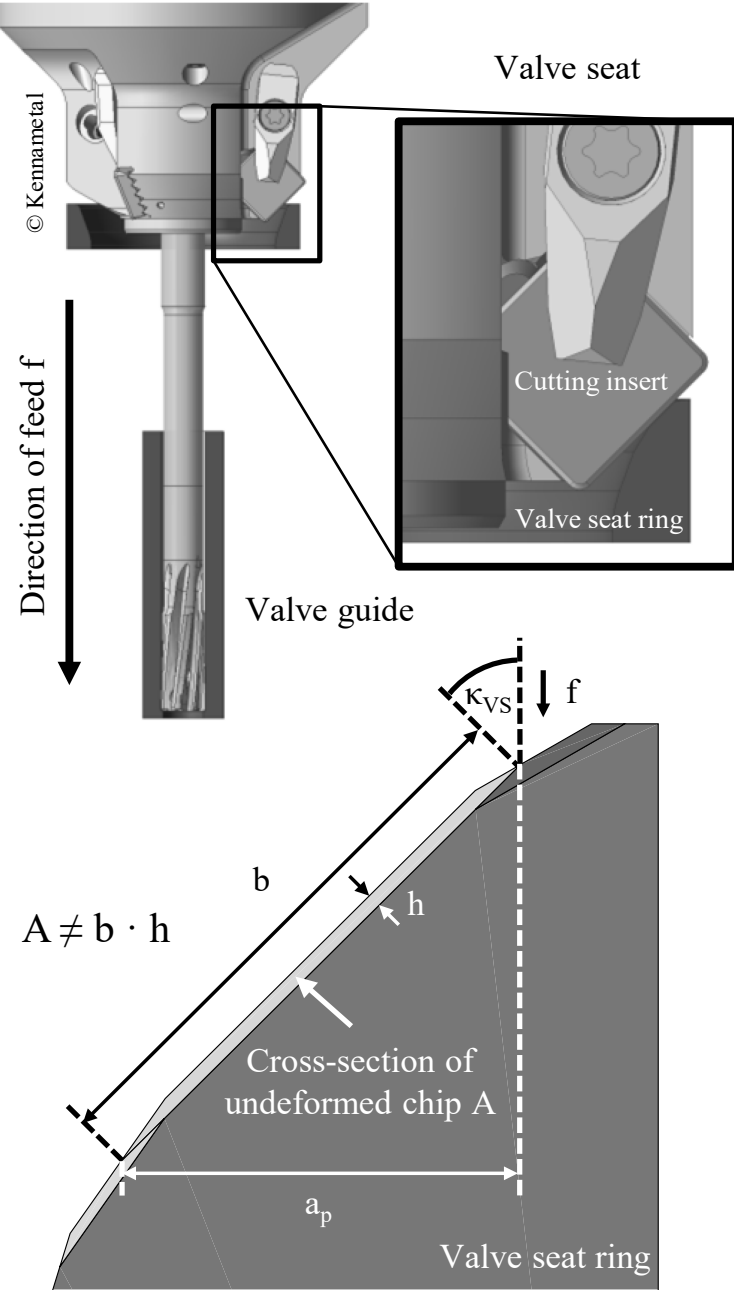

Figure 1: Step tool design and chip parameters in valve guide and seat machining
In the automotive industry, the increasing restrictions on emissions present a challenge for original equipment manufacturers (OEM). Engine downsizing is one way to meet these demands [1]. Here, the thermo-mechanical load on the valves and valve seats is increased, especially at the exhaust. Today, materials with high thermal hardness, high tensile strength, and sufficient thermal conductivity such as powder metallurgy (PM) high-speed steels are more frequently used. These developments pose challenges to fine machining operations and require further investigation of the process and the cutting materials [2]. The tribological system, consisting of the valve and valve seat, seals off the combustion chamber from the environment. The valve guide positions the valve regarding the valve seat. As defined by Klocke et al. [3], the valve-seat ring contains a superposition of functional criteria: mechanical, thermal, tribological, optical, and flow functions. The machined valve seat must resist the cyclic mechanical load approximately 300 billion times during the course of its lifetime of making contact with the valve [4]. Secondly, due to the hot flue gases flowing along the seat ring, it must be heat resistant. At the same time, the thermal conductivity must be high to prevent the valve from thermal overloading. $85 \%$ of the arising heat must be discharged by the valve seat ring [4]. Furthermore, it must fulfil its tribological function to avoid valve failure. 
Uncertainty in machining processes significantly influences the product characteristics during its lifecycle. Hole making and finishing processes consume $89 \%$ of the overall production time of a cylinder head whereby half of them are classified as fine machining operations [5]. Performing these processes, the control of uncertainty is an important key to ensure and even enlarge the product lifetime. The crucial machining processes are often carried out in the final stages of the overall production process. Any variances or failed tolerances due to uncertainty lead to rejects respectively - if this has not been recognized by the quality assurance - to a failure during the life cycle. This always leads to a loss of money. Uncertainty within the process chain hole making and
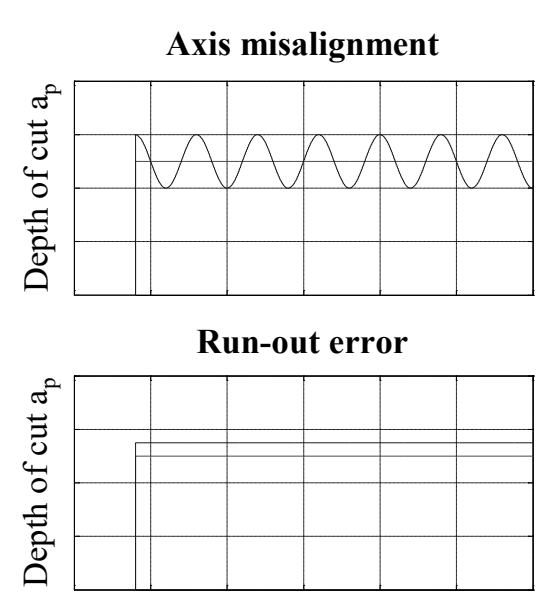

Inclined surface and sloped pilot hole

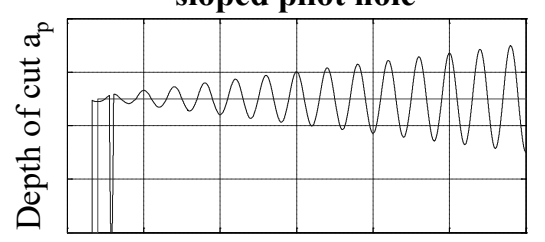

Machining depth

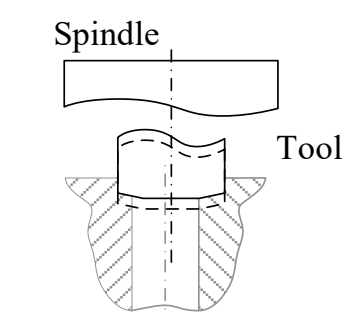

Workpiece
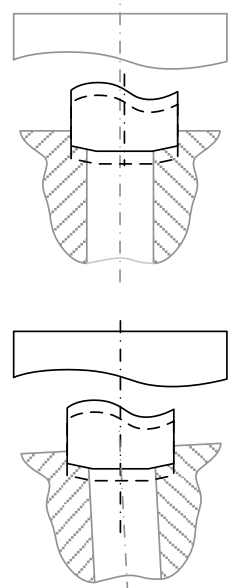

Figure 2: Uncertainty influencing the machining of the valve guide and valve seat

pre-manufactured hole. This leads to a varying, increasing chip cross-section across the reaming depth.

Today, the process of valve seat machining is performed in combination with valve guide reaming using a step tool, as shown in Figure 1. Valve seat machining is characterized by radial and axial offsets as well as varying edge angles of the cutting inserts. Therefore, and due to the geometry of the valve seat blank, the cross-section of the undeformed chip A (Figure 1) of several cutting edges varies with each operation step during machining $[9,10]$. As a consequence, the process forces are not balanced, which causes variation in the radial force and, therefore, deflection of the tool. However, the final geometry has a narrow tolerance window, e.g. with a circularity of $6 \mu \mathrm{m}$ and a concentricity from valve seat to valve guide below $30 \mu \mathrm{m}$. Given these requirements, the machining of valve guide and seat is among the most challenging processes in cylinder head production.

Research has been focusing the modeling of drilling and fine machining processes for years [11]. A major benefit of modeling especially drilling processes is the possibility to illustrate non-observable correlations [12]. In case of reaming and valve seat machining a lateral tool movement influences the resulting workpiece quality. Two different mechanisms are identified that cause a deflection of the tool structure [13]. Low frequency lateral vibrations are independent from the eigenfrequencies of the system and are of regenerative type. These vibrations result in a significant increase in roundness deviation which cannot be improved by variation of the process parameters [14]. Bayly et al. develop a model to predict the polygon shape in reaming process [15]. The modeling is carried out quasi-static and only valid for low cutting speed. The second mechanism, tool deflection 
caused by bending forces, is investigated within the context of reaming processes $[6,7,8]$. The geometry of the tool influences the deflection essentially. Uncertainty by a process fault axis misalignment between workpiece and tool axes can be compensated by using tools with an adjustment angle of $\kappa_{\mathrm{R}}=90^{\circ}$.

Those simulation models focus on a single process step. However, in series production, oftentimes step tools are used and the process chain is more complex. Experimental investigations show that the extension of a process chain in reaming by a pilot reaming process can increase the process reliability significantly [16]. In this paper, a model framework is presented which is able to simulate a multi-stage fine machining process using step tools. The work is performed within the framework of the Collaborative Research Centre (CRC) 805 and with funding from the German Research Foundation (DFG). The tools are supplied by technology partner Kennametal.

\section{Model for determining tool deflection}

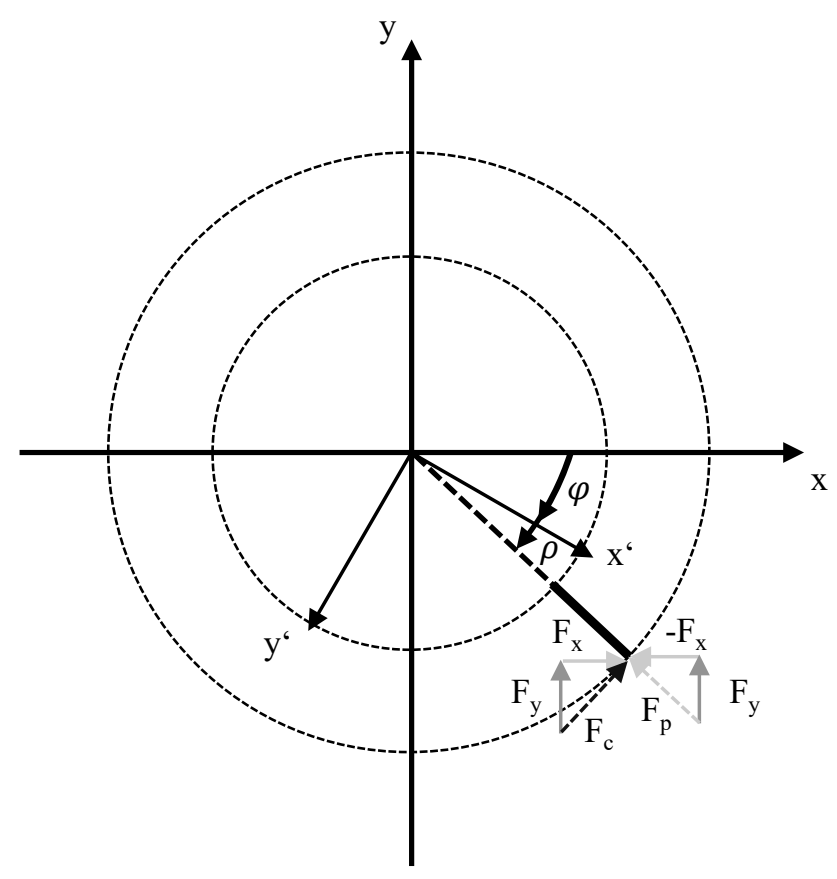

Figure 3: Process forces in fixed and rotating Cartesian coordinate system
The overall model consists of several submodels, see Figure 4. The calculation of the chip cross section $\mathrm{A}$ at the individual cutting edges is made by an intersection calculation by the chip cross section model [9]. The chip cross section serves as an input to the cutting force model, which determines the effective process forces as a function of the chip cross section and the process parameters on the basis of a regression calculation. The regression coefficients are calibrated on the basis of experimental investigations [17]. The determined cutting and passive forces act perpendicular to the feed axis and cause a deflection of the tool structure, see Figure 3. The resulting forces in the $\mathrm{x}$ and $\mathrm{y}$ directions are calculated and used as an input to the tool model. The conversion of the cutting and passive forces on the individual cutting edges is carried out with the aid of the trigonometric functions according to the following calculation formulas:

$$
\begin{aligned}
& F_{x, i}(t)=F_{c, i}(t) \cdot \sin \left(\varphi(t)+\rho_{i}\right)-F_{p, i}(t) \cdot \cos \left(\varphi(t)+\rho_{i}\right) \\
& F_{y, i}(t)=F_{c, i}(t) \cdot \cos \left(\varphi(t)+\rho_{i}\right)+F_{p, i}(t) \cdot \sin \left(\varphi(t)+\rho_{i}\right)
\end{aligned}
$$



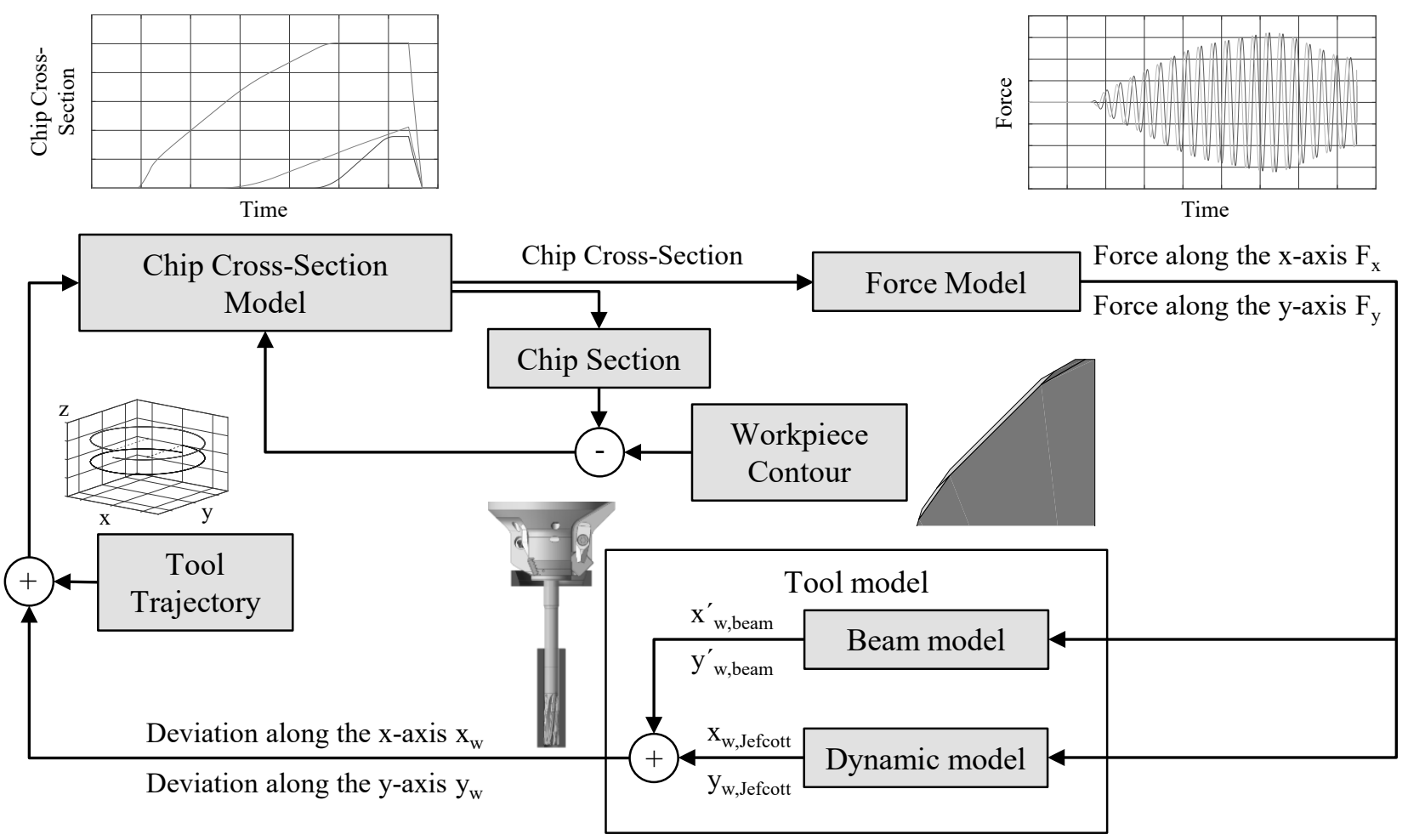

Figure 4: Dynamic model for prediction of bore quality

Subsequently, the force components in both directions are added vectorially. The tool model is then used to calculate the deflection of the tool structure. A Jefcott rotor with two mass discs forms the basis for calculating the deflection. A characteristic of the reaming process is that the tool is geometrically constraint during the stationary process phase, due to its radial land that have a primary clearance angle of $0^{\circ}$. Due to the inclination of the tool in its forced position, it is deflected further beyond the machining depth. Tool inclination at each time step is calculated using a bar model based on Bernoulli's theory. The total deflection of the tool structure in the stationary phase thus results approximately to

$$
\begin{aligned}
& x_{w}(t)=x_{w, J e f c o t t}(t)+x^{\prime}{ }_{w, \text { beam }}(t) \cdot \Delta \mathrm{f}_{\mathrm{z}}(\mathrm{t}) \\
& \mathrm{y}_{\mathrm{w}}(\mathrm{t})=\mathrm{y}_{\mathrm{w}, \text { Jefcott }}(\mathrm{t})+\mathrm{y}^{\prime}{ }_{\text {w, beam }}(\mathrm{t}) \cdot \Delta \mathrm{f}_{\mathrm{z}}(\mathrm{t})
\end{aligned}
$$

The model extends the consideration of uncertainty in fine machining processes by the so far neglected disturbance variables that result from the axial run-out of the boring surface. Furthermore, in contrast to earlier models, the machining processes is simulated completely, and two consecutive machining steps can be simulated. Hence, the previous pilot drilling processing can be modelled.

\section{Model validation}

The validation of the model is based on experimental investigations of valve guide and valve seat machining. For this purpose, self-developed devices that allow for reversible workpiece clamping are used, see Figure 5. Two types of reaming tools, both featuring six cutting edges over the circumference that are divided unequally to avoid low frequency lateral vibrations, are used in the investigations. The first tool features an adjustment angle of $\kappa_{R}=90^{\circ}$, whereas the second tool has an adjustment angle of $\kappa_{R}=65^{\circ}$. Both tools have a further chamfer to protect the cutting corner. The tool used during the experimental investigations of the valve seat machining is equipped with three cutting edges with adjustment angles of $\kappa_{\mathrm{VS}}=35^{\circ} / 45^{\circ} / 60^{\circ}$. 


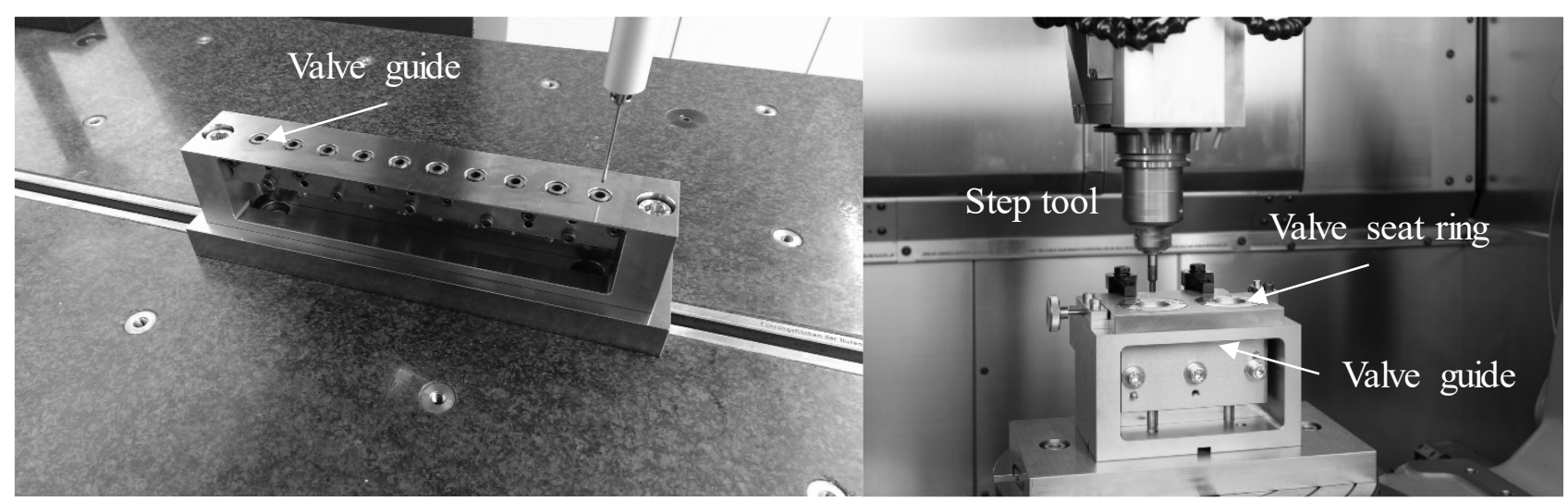

Figure 5: Devices for reproducing the machining processes in the cylinder head of an internal combustion engine

After processing, the machined components are measured on a coordinate measuring machine of type Leitz PMM 864. The valve guide is measured in seven levels at varying depths between $0.5 \mathrm{~mm}$ to $38 \mathrm{~mm}$. The radial deviation of the reamed borehole is calculated from the difference between the centers of the first and last measurement plane in the radial direction. When valve guide and valve seat are simultaneously machined, the valve guide's sealing surface is additionally measured. In this case, the concentricity of the components is calculated based on the position of the sealing surface of the valve seat.

\section{Valve guide reaming}

The validation of the model is done by means of experimental investigations. In the case of valve guide machining using reaming tools, an inclination of the boring surface of $0.75^{\circ} \pm 0.05^{\circ} \mathrm{mm}$ was measured randomly. Based on the reaming tool diameter $\mathrm{d}=6 \mathrm{~mm}$, this corresponds to an axial runout of $0.08 \mathrm{~mm} \pm 0.05 \mathrm{~mm}$. However, some of the experimental results show a large standard deviation (see Figure 4). It is known from previous investigations that the transient process phase has decisive influence on tool deflection $[15,16]$. Hence, the simulations are on the one hand performed with the mean value of the axial run-out and additionally with the added/subtracted standard deviation. The simulated values in the following figure are presented in the form of a mean value and the corresponding error band. Overall, the results show a good congruence between the simulated and the experimentally determined values, see Figure 6. Nearly all investigated configurations show overlapping scattering bands and radial deviations have an average deviation of $10 \%$. Due to increasing process forces, an increase in entry feed leads to a slight increase in radial deviation. Individually occurring stronger mean value deviations indicate the influence of unknown und unobserved uncertainty. Since the values for the axial offset between tool and workpiece axis and the axial run-out of the boring surface are based on average values, the clamping situation may cause the model to over- or underestimate some of the experimental values. The comparison of simulation and experiment does not show a general trend. Therefore, a calibration factor for the reaming process is not calculated. 


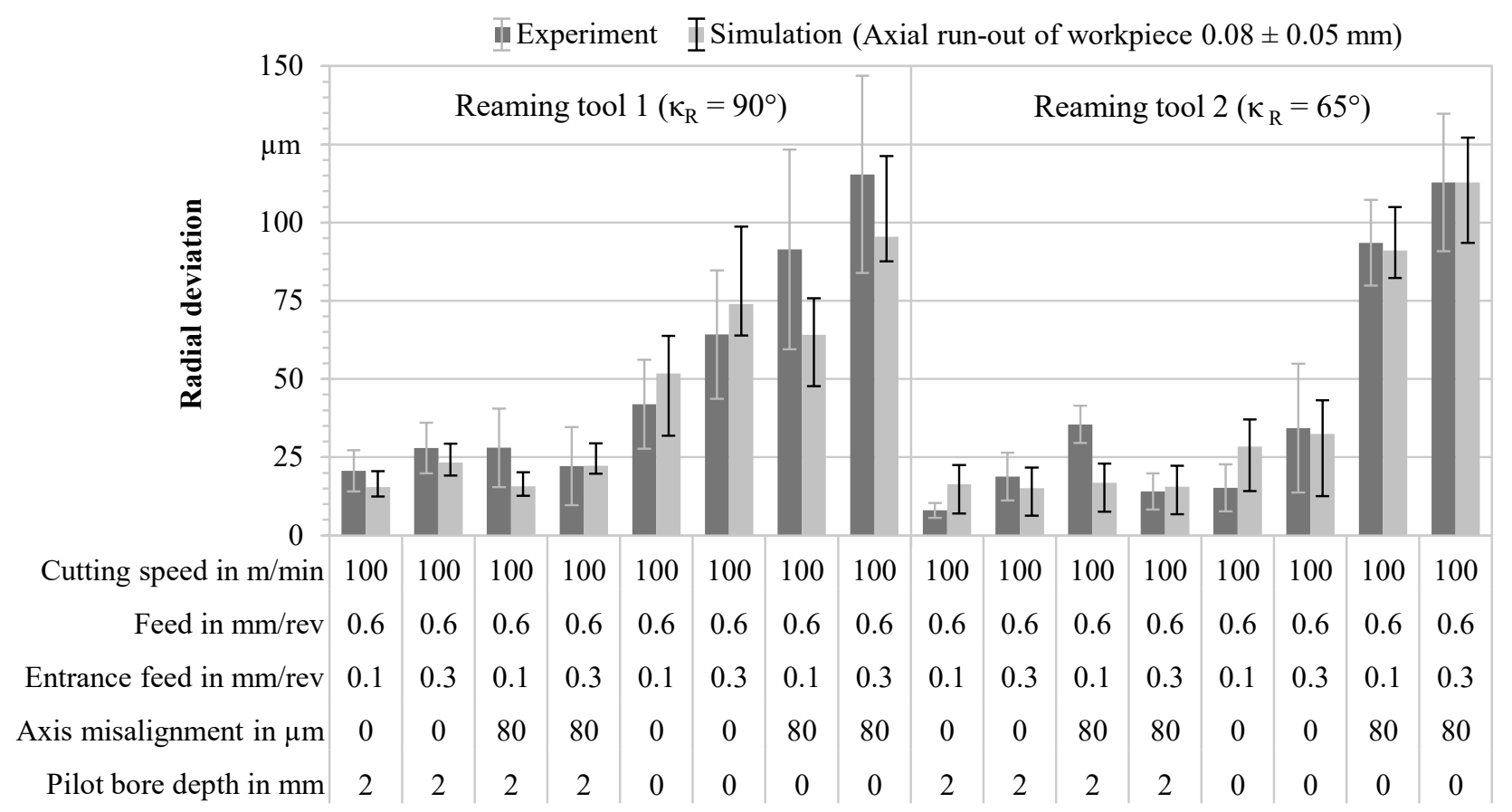

Figure 6: Validation of the reaming process: comparison of the measured and simulated radial deviation of the reamed bores

\section{Valve seat machining}

Validation of valve seat machining is based on the determined radial and feed forces, see Figure 7. For this purpose, experiments using a hydraulic expansion chuck with three cutting edges (setting angles of $\kappa_{\mathrm{vs}}=35^{\circ} / 45^{\circ} / 60^{\circ}$ ) on its circumference are carried out. This configuration represents a typical application in industrial series production. The results show good congruence with regard to the radial force both qualitatively and quantitatively. The average deviation is $1 \%$ and maximum deviation is $11 \%$. With regard to the feed force, the model underestimates the experimental values by an average of $20 \%$. A reason for this deviation may be the acquisition of force data using an analogy process on a turning center [17]. The feed force, which has no immediate influence on the tool deflection, is corrected in the further investigations with a constant calibration factor of $\mathrm{k}_{\mathrm{f}}=$ 1.2. The application of the calibration factor leads to a mean deviation of $1 \%$ and a maximum deviation of $12 \%$.

- Experiment - Simulation

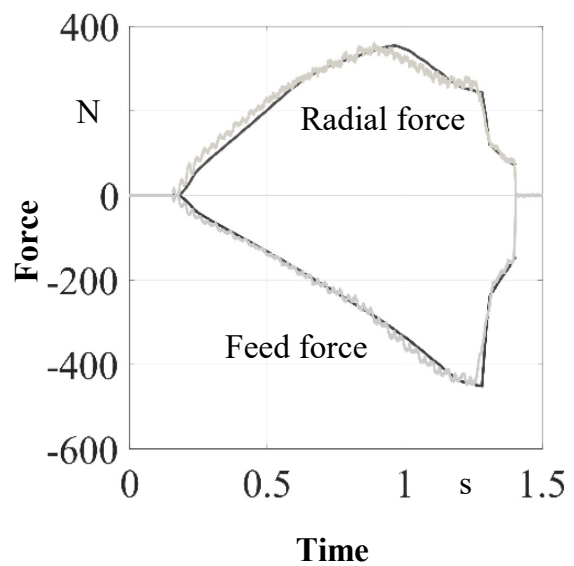

Radial force $\square$ Feed force $\square$ Calibrated feed force

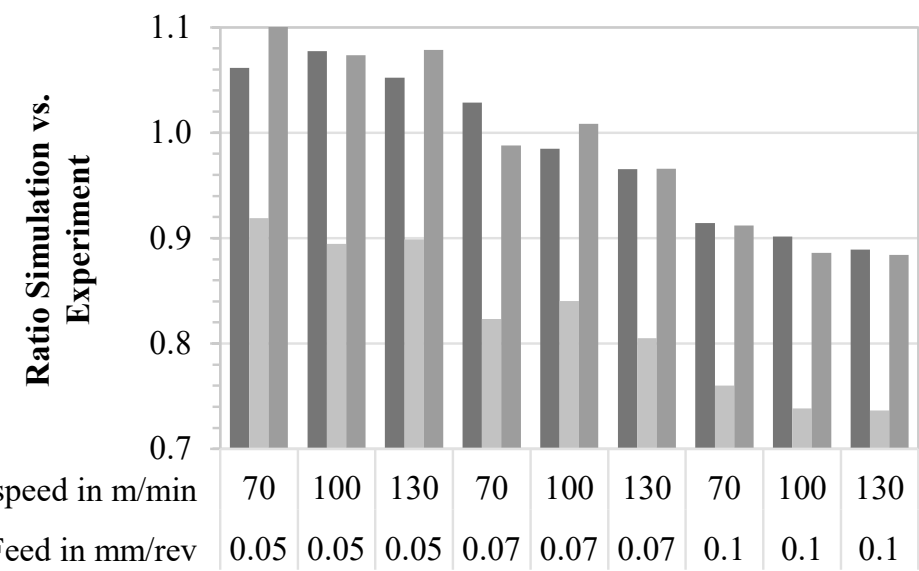

Figure 7: Validation of valve seat machining: comparison of measured and simulated radial and feed forces 
The calibrated model shows for both sub-processes a good congruence of the measured and simulated values. Therefore, an investigation of the influence of uncertainty in the form of disturbances can be conducted. Based on the results, compensation options and adapted process strategies will be developed.

\section{Influence of uncertainty on the radial deviation of the reamed bore}

In a first step, the simulation of the reaming process is expanded by the aspect of uncertainty as a result of the axial run-out of the boring surface. The influence of the axial run-out of the boring surface on the radial deflection of a reaming tool has not been the subject of scientific research. Therefore, this disturbance that in the industrial practice occurs among other things due to reclamping processes is investigated more deeply. For this purpose, a process with ideal axial run-out of the boring surface and an axial run-out of $0.08 \mathrm{~mm} \pm 0.05 \mathrm{~mm}$ (according to the randomly performed measurements during the validation experiments) is assumed.

The results show a dominant influence of the axial run-out of the boring surface on the deviation of the reamed borehole, see Figure 8 . Both tools react highly sensitive to a deterioration of the axial run-out of the boring surface, even if a piloting process was performed prior to the reaming operation. The radial deviation of the reaming borehole worsens by a factor of nine on average. The significant deterioration that occurs with the first tool when the axial offset is superimposed with the deteriorated axial run-out of the boring surface is noticeable. While the tool reacts robustly to the uncertainty of the axial-offset between tool and workpiece if the boring surface is even, a tilt of the boring surface leads to a deterioration of the values by a factor of three. Tool 2 reacts less sensitively. However, it shows an increase in radial deviation by a factor of three, even with an even boring surface. Therefore can be concluded that face cutting reaming tools, as recommended for valve guide machining by [8], only lead to increased robustness and thus to increased process reliability if the boring surface is even. With deteriorating axial run-out, the advantage of simultaneous cutting edge engagement no longer prevails and the tool is significantly deflected as well.

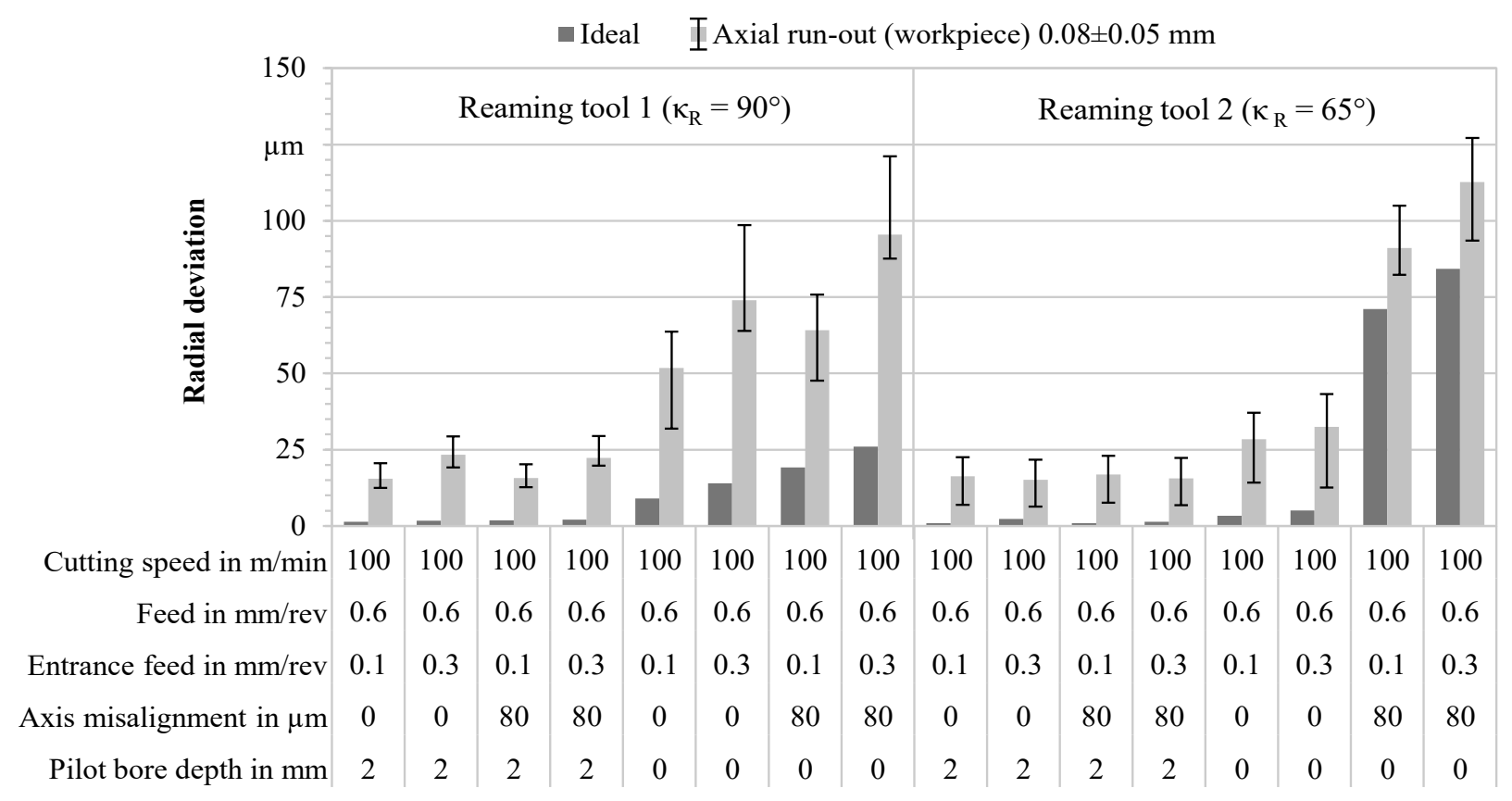

Figure 8: Influence of the axial run-out of the boring surface on the radial deviation of the reamed bore (simulated values)

Based on these findings it can be concluded that foregoing an upstream piloting process cannot be recommended, if the boring surface has not been prepared or the axial run-out is ensured otherwise. Rather it seems advisable to focus the investigations on the geometric design of the pilot reaming tools. This has the potential to control the occurring uncertainty due to the inclination of the boring 
surface by means of an adapted geometry. The previous investigations were carried out using cylindrical pilot tools. In the next step, pilot tools with a compensating counter sink step are simulated. The counter sink step is axially set back compared to the reaming cutting edges. The drilling depth of the piloting process is calculated to ensure that the diameter of the emerging cone on the entry face equals the nominal diameter of the finishing reaming tool. The setting angle of the counter sink step is varied in four stages from $\kappa_{\mathrm{CS}}=15^{\circ}$ to $65^{\circ}$. Due to their geometry, face cutting reaming tools with a setting angle of $\kappa_{R}=90^{\circ}$ do not benefit from a counter sink step that has a diameter similar to the end diameter of the reaming tool. Therefore, only reaming tool 2 is taken into account for simulations.
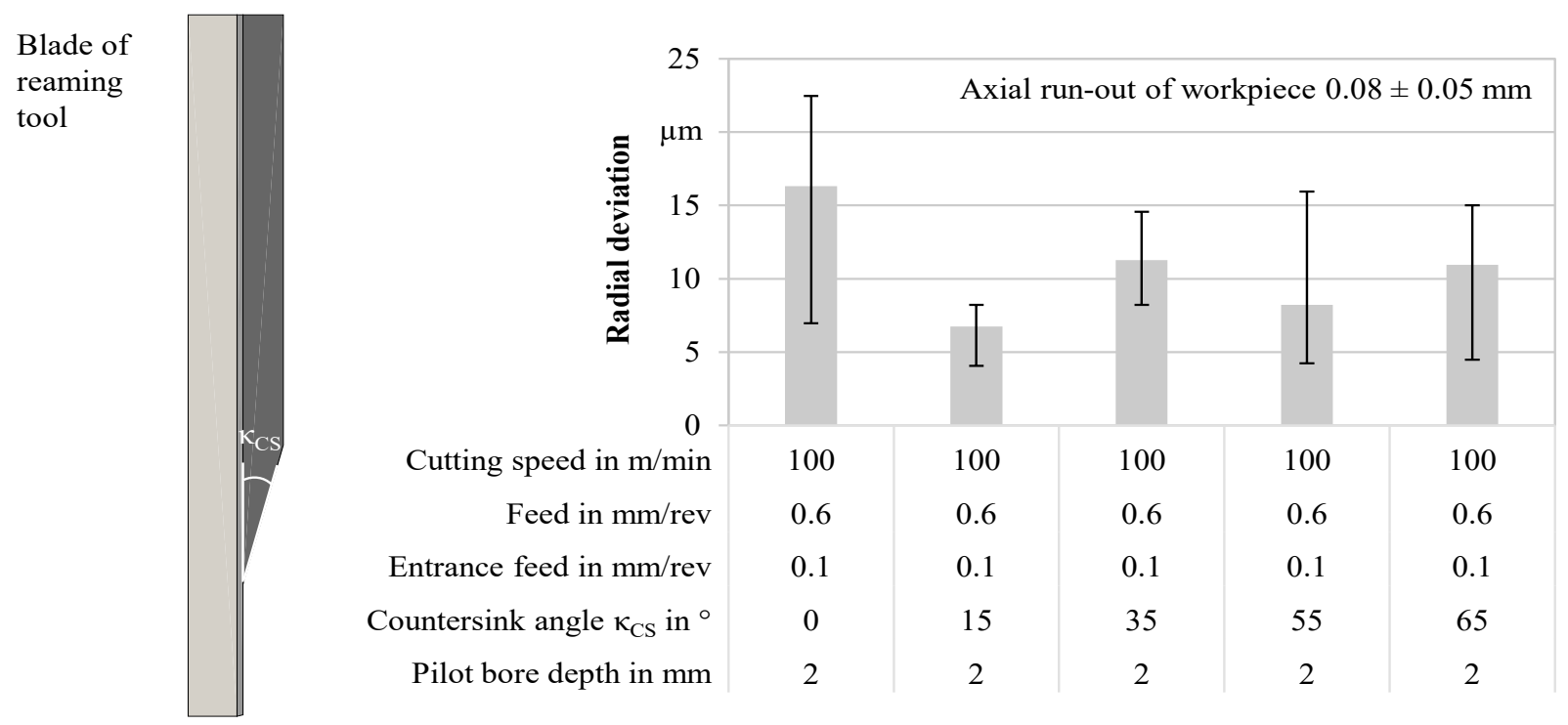

Figure 9: Influence of the geometry of the pilot reaming tool on the radial deviation of the reamed bore at an inclined boring surface (simulated values)

The results of the simulation show that the adjustment of the geometry of the pilot reamer has a measurable influence on the radial deviation of the reamed bore, see Figure 9. In the best case it is possible to reduce the deflection of the finish reamer by $60 \%$. However, the results also show that the geometry of the pilot reaming tool needs to be adapted to the design of the finishing reaming tool to achieve the greatest possible effect and increase process reliability. The simulations show that a non-requirement-oriented adaptation leads to an improvement nonetheless, however, compared to the best result that is achieved with a counter sink angle of $\kappa_{\mathrm{CS}}=15^{\circ}$, the radial deviation shows increases between $22 \%$ and $67 \%$.

\section{Influence of uncertainty on the length of valve seat sealing face}

Nowadays, the valve seat is usually machined with a single tool that has three cutting edges with three different adjustment angles. The adjustment angle of the primary cutting edge that machines the sealing face is usually $\kappa_{V S}=45^{\circ}$. The secondary cutting edges usually have an adjustment angle that is increased or reduced by to $20^{\circ}$. This strategy is commonly used to compensate uncertainty in the form of disturbances. The mean, minimum and maximum length of the sealing face are used as the design value, see Figure 10. The results of the simulation for a tool with three cutting edges show that the uncertainty in the form of an axial offset or a deteriorated axial run-out of the boring surface is geometrically compensated by the tool. In these cases neither the mean length of the sealing face nor its minima and maxima changes significantly. In the case of concentric run-out error of the tool of $10 \mu \mathrm{m}$ in the direction of the $45^{\circ}$ cutting edge, the length of the sealing face increases by $0.1 \mathrm{~mm}$. If a band of $\pm 0.05 \mathrm{~mm}$ around the mean value is set as a tolerance limit, the value is outside the tolerated range. However, the scatter in the length of the sealing face is not affected. The concentric run-out can be adjusted using steerable tool holders. This strategy is often used in industry. 


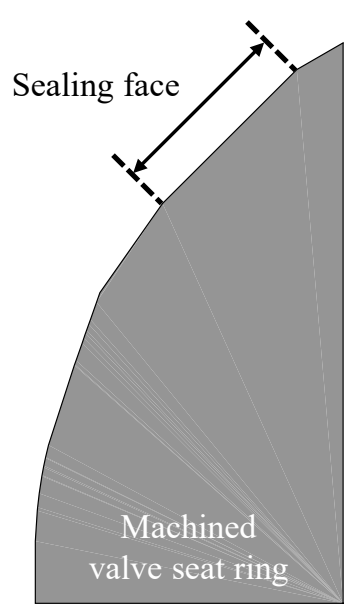

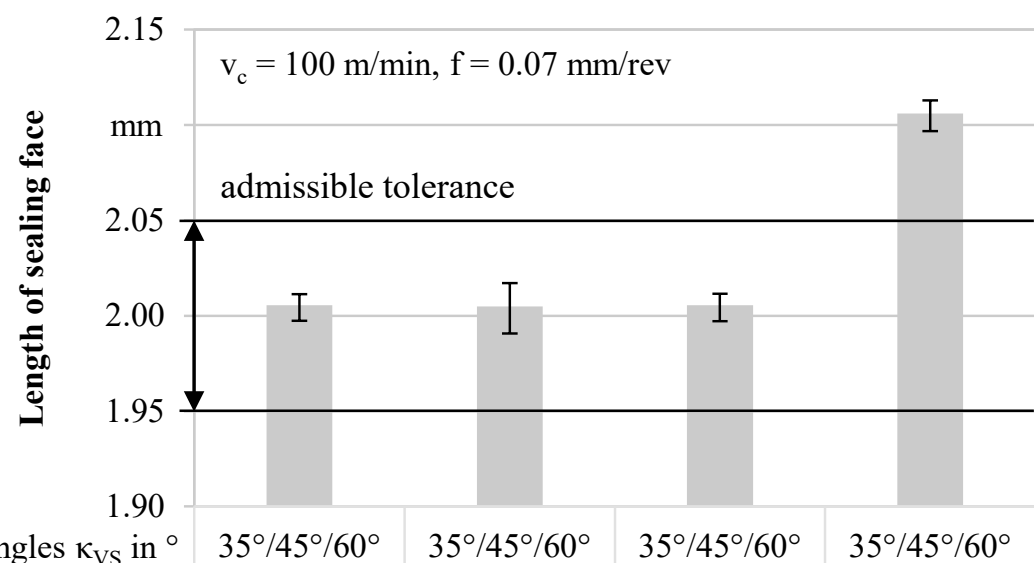

Setting angles $\kappa_{\mathrm{VS}}$ in $^{\circ}$

Axis misalignment in $\mu \mathrm{m}$

Axial run-out of workpiece in $\mu \mathrm{m}$

Concentric run-out of tool in $\mu \mathrm{m}$
0

0

0

0
25
0

0

0

10

Figure 10: Influence of uncertainty in the form of disturbances on the length of the sealing face for tools with three cutting edges (simulated values)

For cost and productivity reasons, the abandonment of secondary cutting edges is increasingly considered. This means that these cutting edges can no longer compensate for the uncertainty which has a direct effect on the length of the sealing face. The simulation results especially show an essential impact of the axial offset between tool and workpiece, see Figure 11. An offset of just 20 $\mu \mathrm{m}$ leads to the lower tolerance limit being undershot.
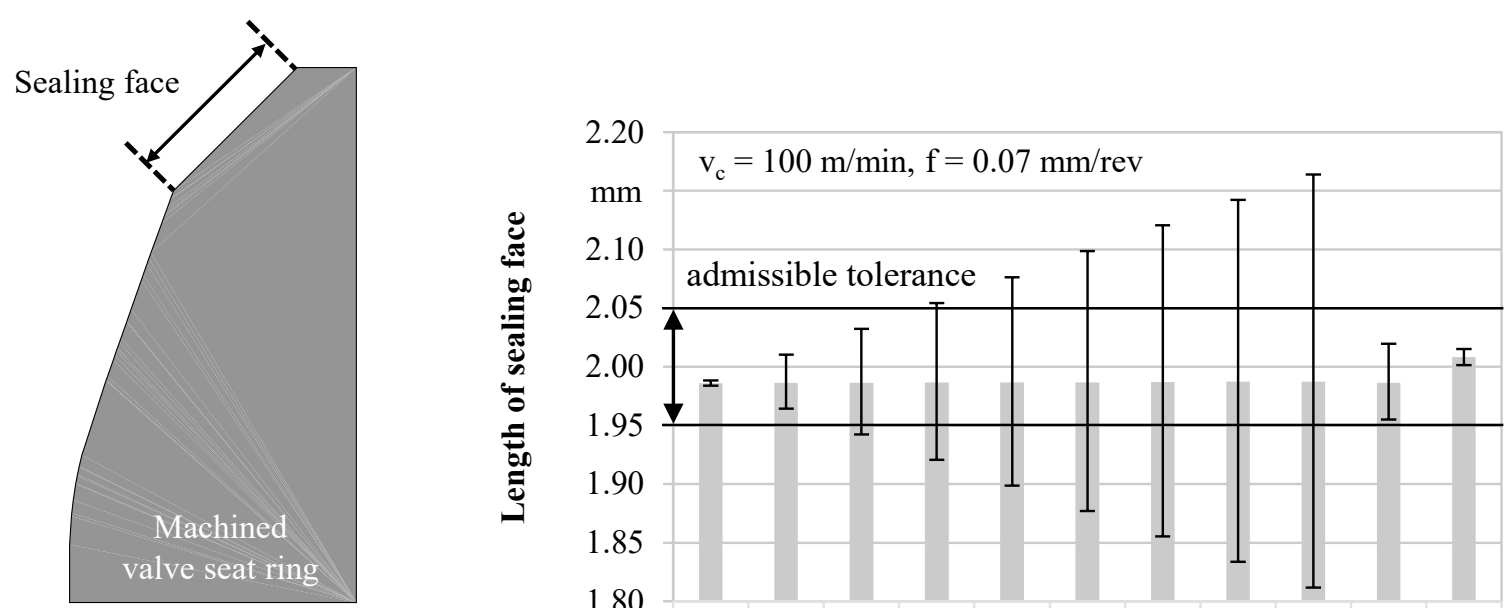

$$
\begin{array}{|r|c|c|c|c|c|c|c|c|c|c|c|}
\hline \text { Setting angles } \kappa_{\mathrm{VS}} \text { in }^{\circ} & 45^{\circ} & 45^{\circ} & 45^{\circ} & 45^{\circ} & 45^{\circ} & 45^{\circ} & 45^{\circ} & 45^{\circ} & 45^{\circ} & 45^{\circ} & 45^{\circ} \\
\hline \text { Axis misalignment in } \mu \mathrm{m} & 0 & 10 & 20 & 30 & 40 & 50 & 60 & 70 & 80 & 0 & 0 \\
\text { Axial run-out of workpiece in } \mu \mathrm{m} & 0 & 0 & 0 & 0 & 0 & 0 & 0 & 0 & 0 & 25 & 0 \\
\text { Concentric run-out of tool in } \mu \mathrm{m} & 0 & 0 & 0 & 0 & 0 & 0 & 0 & 0 & 0 & 0 & 10
\end{array}
$$

Figure 11: Influence of uncertainty in the form of disturbances on the length of the sealing surface for tools with a single cutting edge (simulated values)

Given the accepted tolerances of unprocessed parts that allow for an axial-offset of up to $0.1 \mathrm{~mm}$, a process reliable valve seat machining is not possible. A deteriorated axial run-out of the boring surface and a concentricity error of the tool, which has a significant influence when using threeedged tools, have a less pronounced effect on the length of the sealing surface.

Overall, the simulated results allow the conclusion that a tool with three cutting edges is the best choice for valve seat machining in terms of process reliability and disturbance compensation. The influence of a concentricity error can be minimized by using split chucks to adjust the concentricity. 
In the case of machining using single cutting edge tools process reliability is severely limited. This means that the tolerances of previous machining operations need to be selected much narrower. The influence of upstream processing steps is the subject of ongoing investigations in the Collaborative Research Centre (CRC) 805.

\section{Influence of uncertainty on concentricity of valve seat and guide}

Concentricity of valve seat and valve guide after machining is a decisive criterion for evaluating the quality of the machining process. Typically, values of up to $30 \mu \mathrm{m}$ are accepted. A two-stage process using a tool with three cutting edges and an adjustment angle von $\kappa_{R}=65^{\circ}$ is simulated. The pilot reaming tool features a counter sink angle of $\kappa_{\mathrm{CS}}=15^{\circ}$ which showed the highest level of robustness in prior investigations with tilted boring surfaces. The axial run-out of the boring surface is varied by $\pm 0.05 \mathrm{~mm}$ around its mean value of $0.08 \mathrm{~mm}$. Additionally an axial-offset of both valve seat and valve guide of $80 \mu \mathrm{m}$ is simulated. The concentricity is evaluated in two planes of the valve guide at depths of $0.5 \mathrm{~mm}$ and $38 \mathrm{~mm}$ in relation to the center of the sealing face of the machined valve seat, see Figure 12.

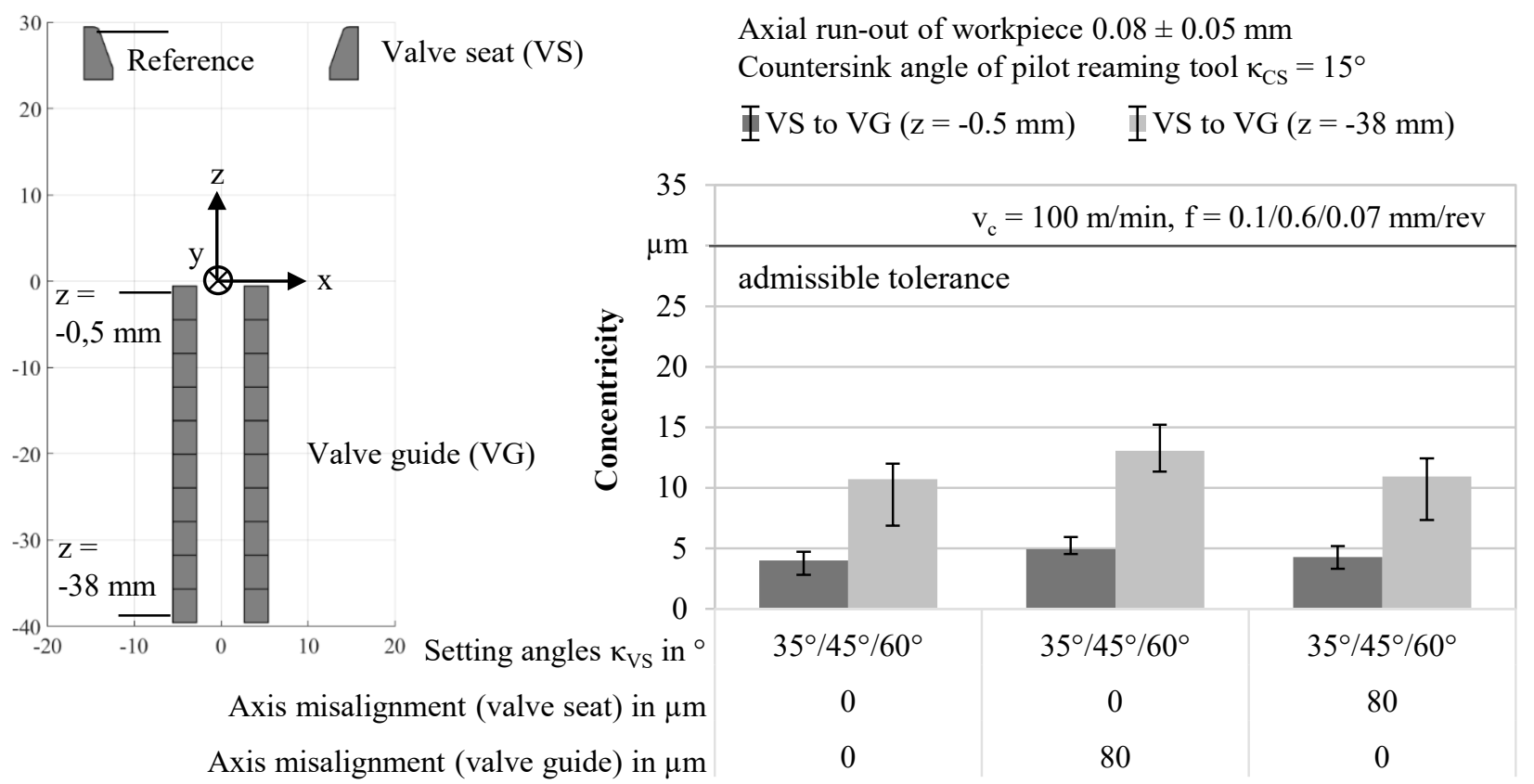

Figure 12: Influence of uncertainty on the concentricity of valve seat and valve guide (simulated values)

The results of the simulation show that the upper tolerance limit of $30 \mu \mathrm{m}$ is clearly undershot, despite existing uncertainty in the form of disturbances. By applying a geometrically adapted pilot reaming tool, the influence of the boring surface tilt on the parts' concentricity is decreased. An axial offset between valve guide and tool axis leads to a marginal deterioration of the concentricity. A comparison of the results at a depth of $0.5 \mathrm{~mm}$ shows only a slight difference of $1 \mu \mathrm{m}$ between the simulated values. However, due to the inclination of the tool this deviation doubles over the course of the drilling depth. This illustrates yet again the reaming tool's sensitivity towards disturbances during the transient entry phase into the workpiece.

\section{Summary and Outlook}

The simulation of interlinked multi-stage machining processes allows for the identification of factors that have significant influence on the quality of processed components. The so far neglected uncertainty due to the axial run-out of the boring surface has a decisive influence on the radial deviation of the reamed borehole and thus on the process reliability of the overall process. By adapting the geometry of the pilot reaming tool, this uncertainty can be controlled. The length of the sealing face is also decisively influenced by uncertainty due to disturbances. A compensation by applying secondary cutting edges increases robustness significantly. Even under the influence of 
disturbances, the concentricity of valve seat and valve guide can be ensured, given that the previous findings are being considered. Future research activities in the CRC 805 will focus on the up to this point unnoticed uncertainty in an interlinked process that also includes upstream process steps. When the application of secondary cutting edges in valve seat machining is waved, this procedure is inevitable to increase the robustness of the overall process against the influence of uncertainty.

\section{Acknowledgement}

The authors would like to thank the German Research Foundation (DFG) for funding the research activities at the Collaborative Research Centre (CRC) 805 - Control of Uncertainty in LoadCarrying Structures in Mechanical Engineering. Tools are supplied by Kennametal within the framework of the project.

\begin{tabular}{|c|c|c|c|c|c|}
\hline Variable & Unit & Description & Variable & $\underline{\text { Unit }}$ & $\underline{\text { Description }}$ \\
\hline $\mathrm{A}$ & $\mathrm{mm}^{2}$ & cross-section of & $\overline{\mathrm{v}_{\mathrm{c}}}$ & $\overline{\mathrm{m} / \mathrm{min}}$ & $\overline{\text { cutting speed }}$ \\
\hline & & undeformed chip & $\mathrm{x}_{\mathrm{w}}$ & $\mu \mathrm{m}$ & deviation of tool \\
\hline$a_{p}$ & $\mathrm{~mm}$ & depth of cut & & & in $\mathrm{x}$-direction \\
\hline$b^{p}$ & $\mathrm{~mm}$ & $\begin{array}{l}\text { width of } \\
\text { undeformed chip }\end{array}$ & $\mathrm{y}_{\mathrm{w}}$ & $\mu \mathrm{m}$ & $\begin{array}{l}\text { deviation of tool } \\
\text { in y-direction }\end{array}$ \\
\hline$f$ & $\mathrm{~mm} / \mathrm{rev}$ & feed per rev. & $\mathrm{x}_{\mathrm{w}}^{\prime}$ & $\mathrm{rad}$ & inclination of tool \\
\hline $\mathrm{f}_{\mathrm{z}}$ & $\mathrm{mm}$ & feed per tooth & & & in $\mathrm{x}$-direction \\
\hline$\Delta \mathrm{f}_{\mathrm{z}}$ & $\mathrm{mm}$ & feed per time increment & $y_{w}^{\prime}$ & $\mathrm{rad}$ & inclination of tool \\
\hline $\mathrm{F}_{\mathrm{c}}$ & $\mathrm{N}$ & cutting force & & & in $\mathrm{y}$-direction \\
\hline $\mathrm{F}_{\mathrm{f}}$ & $\mathrm{N}$ & feed force & $\kappa$ & 。 & tool edge \\
\hline $\mathrm{F}_{\mathrm{p}}$ & $\mathrm{N}$ & passive force & & & angle \\
\hline $\mathrm{F}_{\mathrm{r}}$ & $\mathrm{N}$ & radial force & $\rho$ & $\circ$ & angular pitch of cutting \\
\hline $\mathrm{F}_{\mathrm{x}}$ & $\mathrm{N}$ & force in $\mathrm{x}$-direction & & & edge \\
\hline $\mathrm{F}_{\mathrm{y}}$ & $\mathrm{N}$ & force in $y$-direction & $\varphi$ & $\circ$ & angular position of the \\
\hline $\mathrm{k}^{\mathrm{y}}$ & - & calibration factor & & & tool \\
\hline $\mathrm{t}$ & $\mathrm{s}$ & time & & & \\
\hline
\end{tabular}

\section{References}

[1] van Basshuysen, R.; Schäfer, F. (Hrsg.): Handbuch Verbrennungsmotor - Grundlagen, Komponenten, Systeme, Perspektiven. Vieweg-Verlag, Wiesbaden, 2012.

[2] Jesus Filho, E. S., et al.: P/M Valve Seat Inserts: Machinability and Mechanical Characterisation. No. 2005-01-0717. SAE Technical Paper, 2005.

[3] Klocke, F., Brinksmeier, E., Weinert, K.: Capability profile of hard cutting and grinding processes, CIRP Annals-Manufacturing Technology 54.2:22-45, 2005.

[4] N. N.: Ventiltrieb - Systeme und Komponenten. Mahle GmbH (Hrsg). Wiesbaden: Vieweg Verlag 2013.

[5] Koppka, F.: A contribution to the maximization of productivity and workpiece quality of the reaming process by analyzing its static and dynamic behavior, Shaker Verlag, Aachen, 2009.

[6] O. Bhattacharryya, S.G. Kapoor, R.E. DeVor: Mechanistic model for the reaming process with emphasis on process faults, International Journal of Machine Tools and Manufacture, 46 (2006), 836-846.

[7] O. Bhattacharryya, M.B. Jun, S.G. Kapoor, R.E. DeVor: The effects of process faults and misalignment on the cutting force system and hole quality in reaming, International Journal of Machine Tools and Manufacture, 46 (2006), 1281-1290.

[8] Hauer, T.: Modellierung der Werkzeugabdrängung beim Reiben - Ableitung von Empfehlungen für die Gestaltung von Mehrschneidenreibahlen. Shaker Verlag, Aachen, 2012. 
[9] Abele, E, Bölling, C.: Modellierung der geometrischen Eingriffsbedingungen bei der Ventilsitzbearbeitung am Zylinderkopf, Werkstattstechnik online 11/12 (2014) 735-740.

[10] Li, Y., et al.: Force modeling for cylindrical plunge cutting, Int. J Adv Manuf Technol, 16:863$870 ; 2000$.

[11] Abele, E., Elsenheimer, J., Hohenstein, J., Tschannerl, M.: Influence of drill dynamics on bore quality, Annals of the CIRP 54 (2005) 83-86.

[12] Biermann, D.; Kersting, M.; Surmann, T.: Simulation der Prozessdynamik beim Einlippenbohren, Werkstattstechnik online 11/12 (2007) 879-883.

[13] Ellermeier, A.: Methode zur Standwegprognose für lange Vollhartmetall-Spiralbohrer zum Tiefbohren auf Bearbeitungszentren, Shaker Verlag, Aachen, 2008.

[14] Tschannerl, M.: Ein Beitrag zur Qualitätssteigerung beim Bohren mit VHM-Spiralbohrern unter Berücksichtigung radialer Schwingungen und Kräfte. Shaker Verlag, Aachen, 2007.

[15] Bayly, P. V. et al.: Analysis of Tool Oscillation and Hole Roundness Error in a Quasi-Static Model of Reaming. In Journal of Manufacturing Science and Engineering 123 (2001), 387.

[16] Bölling, C.; Güth, S.; Abele, E.: Control of Uncertainty in High Precision Cutting Processes. Reaming of Valve Guides in a Cylinder Head of a Combustion Engine. Uncertainty in Mechanical Engineering II. Trans Tech Publications (2015) 153-161.

[17] Bölling, C., Kuhne, M., Abele, E.: Modeling of Process Forces with Consideration of Tool Wear for Machining of Sintered Steel Alloy for Application to Valve Seat in a Combustion Engine. Production Engineering: WGP, Springer Verlag, Heidelberg, 11, 4-5 (2017) 477-485. 